\title{
APRESENTAÇÃO DO DOSSIÊ
}

\section{TRANSTORNAR HÁBITOS EDUCATIVOS: O QUE AINDA É POSSÍVEL EM TERRAS ARRASADAS?}

\author{
Valéria Cazetta ${ }^{1}$ \\ Ana Maria Hoepers Preve ${ }^{2}$ \\ Maria Helena Lenzi ${ }^{3}$
}

\begin{abstract}
[...] a possiblidade de um outro mundo nunca ocultou os outros do mundo, invisíveis e incalculáveis, com os quais ela [a geografia] não acaba de se haver, cabendo-lhe decidir, a cada vez, se os subjugará, se obstruirá sua passagem ou se com eles fará potentes alianças, aquelas que mudarão completamente a
\end{abstract} natureza de nossas práticas. (GODOY, 2013, p. 221)

Neste dossiê apresentamos estudos concluídos em dois grupos de pesquisa: o primeiro intitulado "Geografias de experiência", e o segundo "Grupo de Pesquisa em Culturas Visuais e Experimentações Geográficas" (Miragem) ${ }^{6}$, coordenados, respectivamente, pelas professoras Ana Maria Hoepers Preve e Valéria Cazetta, cuja parceria vem se consolidando no sentido de um comum: a cartografia como potência de inventar mundos e a problematização das ambiências educacionais contemporâneas. Por um lado, a cartografia como qualidade de acompanhar processos para dizer o que ainda precisa ser dito em situações diversas a partir de nossas investigações em andamento e daquelas de nossos/as convidados/as para o dossiê; e, por outro, a cartografia da geografia, responsável por assegurar a produção de mapas ancorada na equivalência do espaço e sua apresentação como possibilidade de outros mundos. A Professora Maria Helena Lenzi, por sua vez, também integra o Miragem e possui conexões de estudo e publicações com ambas as professoras citadas.

Dos nossos encontros, esse compilado, constituído de estudos tributários tanto de pesquisas e trabalhos de orientação, como de outros/as pesquisadores/as não vinculados/as diretamente aos grupos suprarreferidos, para pensar uma educação situada nos limites entre o trágico, os aprisionamentos e aquilo que pede passagem no tempo-espaço dos dias atuais. Nessas fronteiras, nenhum horizonte avistado apresenta garantias, territórios seguros e tranquilizantes. No entanto, estamos cada vez mais imobilizados/as e apegados/as a um mundo de representações, a despeito do excesso de circulação dos corpos, humanos e não-humanos; e

\footnotetext{
${ }^{1}$ Professora da Escola de Artes, Ciências e Humanidades (EACH) - Universidade de São Paulo (USP). E-mail: vcazetta@usp.br.

${ }^{2}$ Professora do Departamento de Geografia e no Programa de Pós-Graduação em Educação/Centro de Ciências Humanas e da Educação (FAED) - Universidade do Estado de Santa Catarina (UDESC). E-mail: anamariapreve@gmail.com.

${ }_{3}$ Professora do Departamento de Geociências - Universidade Federal de Santa Catarina (UFSC). E-mail: m.h.lenzi@ufsc.br.

${ }^{4}$ GODOY, Ana. Mídia, imagens, espaço: notas sobre uma poética e uma política como dramatização geográfica. In: CAZETTA, Valéria; OLIVEIRA JR., Wenceslao M. (Org.). Grafias do espaço: imagens da educação geográfica contemporânea. Campinas, SP: Alínea Editora, 2013. p. 209-222.

${ }^{5}$ Para mais informações ver: 〈https://geosdeexp.wordpress.com/>.

${ }^{6}$ Para mais informações ver: <http://miragemcveg.blogspot.com.br/>.
} 
do excesso de informações que caracteriza nosso momento, isto é, na contemporaneidade tudo circula para estar sempre no mesmo lugar, e nossa subjetividade fica, assim, ameaçada de petrificar-se (GUATTARI, 1962) ${ }^{7}$.

Nosso desejo foi que os/as autores/as aqui reunidos apresentassem caminhos investigativos atravessados por experimentações, as quais pudessem constituir mapas de outros modos de viver, mapas de outros mundos, mapas de se relacionar, mapas de produzir e de se educar, envolvendo a produção de tantos outros mundos invisíveis e incalculáveis, dando sentido ao que ainda é possível em terras arrasadas. Assim, tratou-se mais de criar espaços nessas terras arrasadas tão gastas por repetições, protocolos, planos, diretrizes, do que apresentar soluções de como sanar um completo esgotamento dos meios educacionais ou do solo - pelo excesso de insumos agrícolas lançados sobre os cultivos. O que podem tais terras? Interessou-nos movimentos do pensamento que possibilitam uma composição com esse plano arrasado, com essa terra, que, de tão gasta, parece não evidenciar mais nenhum tipo de ocupação. Por isso, sugerimos aos/às autores/as que trouxessem à tona algo do que fazem e estudam e que pode ser novidade, no sentido daquilo que movimentou e transtornou o hábito, o costume, causando deslocamentos dos gestos educacionais corriqueiros. Tais terras, antes de se abrirem ao que pode, são majoritariamente apropriadas por grandes sistemas de plantações; estas esgotam os solos assim como fazem as grandes propostas educacionais atuais ao garantirem uma educação pela via da escolarização apenas. Desse esgotamento esperamos um novo habitar dos territórios educacionais, como evidenciaram os/as autores/as em seus textos ao apresentarem movimentos de pesquisa, sinalizando que a terra arrasada ainda pode alguma coisa.

Gilles Deleuze (2010, p. 59) diz: "toda a questão gira em torno do fato majoritário [...]. A maioria não designa uma quantidade maior, mas, antes de tudo, o padrão em relação ao qual as outras quantidades, sejam elas quais forem, serão consideradas menores" e, nesse sentido, acreditamos na potência desses textos como ativadores de uma ideia de minoritário, à medida que as problemáticas neles desenvolvidas desviam-se de modelos generalistas relacionados à educação. O que justifica nossa junção, bem como a dos/as autores/as diz respeito à aposta: para pensar em educação é preciso transtornar hábitos e acostumamentos. Operar com o minoritário trata-se de produzir desvios nos modelos; escavar algo que já estava lá no interstício do solo ou de uma dada ambiência educacional. Escavar não no sentido de descobrir algo novo, mas de atualizar o que brota das fraturas nos espaços, que "nunca ocultou os outros do mundo" (GODOY, 2013, p. 221) $)^{9}$.

A educação no contexto desse dossiê é concebida menos com o que se passa em contextos escolares, e mais com as possibilidades que escapam aos contornos e controles do que é escolarizante. Educar é tudo aquilo que transforma o pensamento, fazendo-o variar para além do convencionalmente dado como direção única. Esses textos, assim, esgotam o possível do que está dado e entram num campo de exaurir as palavras na forja de possibilidades outras, nosso mote aqui: trazer com os textos uma força que se avizinha do impossível em terras onde quase nada mais parece possível. O que pode uma terra arrasada?

Trabalhamos com a hipótese de que há importância na atualidade - tendo em vista as críticas feitas à escola e aos saberes que ali circulam, no nosso caso o saber como informação apenas - de uma analítica de situações educacionais cotidianas como subsídios à formação de

\footnotetext{
${ }^{7}$ GUATTARI, Félix. Práticas ecosóficas e restauração da cidade subjetiva. Revista Tempo Brasileiro, v. 1, n. 1, p. 9-25, 1962.

${ }^{8}$ DELEUZE, Gilles. Sobre o teatro: um manifesto de menos; o esgotado. Tradução de Fátima Saadi, Roberto Machado e Ovídio de Abreu Filho. Rio de Janeiro, RJ: Jorge Zahar, 2010.

${ }^{9}$ GODOY, Ana. Mídia, imagens, espaço: notas sobre uma poética e uma política como dramatização geográfica. In: CAZETTA, Valéria; OLIVEIRA JR., Wenceslao M. (Org.). Grafias do espaço: imagens da educação geográfica contemporânea. Campinas, SP: Alínea Editora, 2013. p. 209-222.
} 
educadores/as na contemporaneidade. Pensamos, desde nossos estudos e andanças pelo contexto acadêmico, que a organização desse dossiê alcançará outros/as pesquisadores/as que já estão no percurso exaustivo da composição com as terras arrasadas, movimentando, desse modo, problemáticas educacionais vivas que podem catapultar potenciais forças de composição com nosso mundo.

Apresentemos, então, cada um dos textos.

Cartografias e literatura fantástica: leituras outras na educação geográfica, de Deyse C. B. Fabrício e Valéria Cazetta, versa acerca de estudo no âmbito da cartografia escolar, especialmente, mapas históricos e literatura épica no contexto de aulas de geografia para o Ensino Médio da Educação Básica. Mapas de mundos imaginados e fictícios são frequentes, inclusive quando se acessa o sítio Youtube com vídeos e tutoriais acerca da confecção de mapas com temáticas épicas, os quais não são concebidos por profissionais da cartografia institucionalizada, asseveram as autoras. Ademais, o aumento na publicação de livros e jogos infantojuvenis fez com que o interesse desse público para a temática épica, permeada pelas cartografias de mundos fictícios, também fosse ampliada. O eixo empírico do estudo, delineado por meio de atividades educativas, foi pensado com a finalidade de implicar os/as estudantes para a literatura épica e os mapas históricos, resultando em mapas elaborados por eles/as, os quais possibilitaram conhecer as carto-falas que os/as impeliram a produzi-los. Esse tipo de cartografia atesta para a diversificação dos atores que realizam mapeamentos no mundo contemporâneo, dialogando com mapas escolares que apresentam ideias muito padronizadas do que é cartografia. Os mapas de mundos fictícios confeccionados pelos/as estudantes, demonstraram um repertório cartográfico bem mais vasto do que aquele comumente imaginado por nós, trazendo maior amplitude à cartografia escolar, quando se leva em consideração o que pode a cartografia no encontro entre a cartografia convencional e a literatura épica.

Em Geografias do artista quando coisa: marcelo moscheta e manoel de barros como intercessores geográficos, Wenceslao Machado de Oliveira Júnior e Gisele Girardi problematizam que tanto geógrafos/as como professores/as de geografia perceberam, já há algum tempo, na arte e nos artistas, potências para o fazer e o pensar geográficos. Ao partirem do entendimento do processo criativo de artistas, quando apropriam-se dos produtos da ciência como matérias-primas para produzirem suas próprias obras, Oliveira Júnior e Girardi argumentaram: obras de arte que tomaram produtos da ciência, no caso a "geográfica" e a "cartográfica" como elemento de composição, conduziram o pensamento científico (geográfico) a mover-se, a pensar na diferença e, quiçá, em outras políticas e poéticas espaciais. Para compor pensamentos e argumentos sobre educação, linguagens e geografias a partir do campo problemático esboçado, os autores empregaram obras do artista Marcelo Moscheta como forças intercessoras, pois nelas são recorrentes temas do escopo científico da geografia: terra, fronteira, espaço, território, paisagem e imagens cartográficas. Moscheta articula, assim, fazeres clássicos das mediações da ciência geográfica com o real na composição de suas obras, tais como: mapas, imagens de satélite, fotos de paisagens, perfis topográficos, coleções, trabalhos de campo. Tais fazeres são reconhecíveis e desestabilizados a um só tempo, abertos que estão a outras possibilidades expressivas. Nesse jogo de intercessores mútuos, entre ciência e arte, Oliveira Júnior e Girardi buscaram matéria-prima para conversar sobre como hábitos geográficos-científicos, ao virarem matéria-prima de obras de arte, podem transtornar hábitos educativos e expandir as possibilidades para a Geografia, a partir das linguagens audiovisual e cartográfica.

Oficinas começam à maneira de ruderais intitula-se o texto de Danilo Stank Ribeiro e Ana M. H. Preve, no qual abordam a oficina na díade: lugar físico ou fictício e forma de ocupar um dado território educativo, implicado com o modo de habitá-lo, de fazer algo nele por meio do encontro - com o outro, com uma ideia, com um material -, que é sua potência. Ao 
conceberem a oficina dessa maneira, ou seja, como lugar e forma de realização dos encontros educativos, Ribeiro e Preve operam com a ideia de ninho ou toca para pensar as características do lugar onde a oficina acontece, tida como território móvel, feito com materiais muito simples, e que "brotam" à maneira das erva-daninhas. O escopo empírico do estudo foi circunscrito por uma experiência audiovisual, na busca de dar a ver modos de habitar um lugar: do fazer, da atenção, do interceder, do olhar, do colher e do recolher. Variações de um lugar: para vê-lo de outra maneira, para dizer de outro modo, para habitá-lo na semeadura, mesmo correndo o risco de sucumbir a estas mesmas terras, outrora arrasadas.

Em Mapas de um espaço-tempo: uma cartografia do território escolar na sociedade de controle, Mirele Corrêa e Giceli Cervi problematizam as potencialidades do corpo em espaço de escolarização, objetivando discutir a relação entre corpo, currículo e território escolar na atual sociedade de controle descrita por Gilles Deleuze. Por meio da cartografia, entendida pelas autoras como reversão metodológica ao consistir numa experimentação do pensamento e no acompanhamento de processos inventivos, o texto aborda as experiências realizadas numa escola pública estadual do município de Blumenau (SC) e falas de professores/as e estudantes que fazem parte de um currículo específico conhecido como Ensino Médio Inovador - política pública de educação em tempo integral, instituída pela Portaria $n^{\circ}$. 971, de 09/10/2009 (BRASIL, 2009). Corrêa e Cervi também analisam os documentos regulamentadores da operacionalidade desse currículo na instituição pesquisada.

Guilherme Carlos Corrêa, Fernanda Rigue e Tascieli Feltrin abordam n'A formação de professores no Brasil e sua mecânica de subjetivação, a emergência da Química como disciplina escolar, bem como sua consolidação e permanência no Sistema Nacional de Educação. Nesse estudo, o autor e as autoras realizam um panorama sobre o percurso de instauração da Química escolar, desde o período colonial até a Ditadura Militar, e, a partir dessa linha cronológica movediça, apresentam o jogo de forças que configurou os cursos de formação de professores nos dias atuais. O ensino de Química no contexto escolar constituiu-se a partir de um conjunto de saberes desarticulado, que, com a vinda da Família Real para o Brasil, passou a ser enunciado sob a chancela científica, ganhando importância estratégica no campo educacional devido a sua relevância em decisões econômicas, sociais e militares de todos os países considerados desenvolvidos, os quais forneceram o modelo de desenvolvimento adotado pelo Brasil.

Em Hans Bellmer \& David Nebreda: órgãos desterritorializados, Jonathan Mendes Tavares apresenta dois conjuntos de objetos artísticos: um produzido pelo escultor alemão Hans Bellmer (1902 - 1975), e o outro de autoria do fotógrafo espanhol David Nebreda de Nicolas (1952). Buscando estabelecer meios de compreender a mutação física efetuada nos corpos, Tavares usa as obras dos respectivos artistas para pensar quando um corpo deixa de se adequar ao modelo de organização anâtomo-científica. Para Tavares os corpos criados por Bellmer e Nicolas pervertem a anatomia orgânica para extrair dela, não suas formas, mas as forças capazes de perturbar definições ordinárias que se dedicam a estratificar o corpo nas formas provisórias por meios das quais é apresentado. As obras desses dois artistas foram tomadas pelo autor como "evidências" de regimes visuais artísticos que se opõem à estratificação do corpo produzida pela imagem anatômica - apoiada no decalque de formas sedentarizadas passíveis de se efetuarem via matéria morta.

Sobre projecionistas, imagens e educação: movimentos cartográficos do pensamento em um jogo de dados educacional, Ingrid Rodrigues Gonçalves aborda o trabalho dos operadores cinematográficos (ou projecionistas), no contexto de transição do suporte padrão de exibição cinematográfica das películas fílmicas para os formatos digitais. Ao serem tomados de assalto por demandas operacionais relacionadas ao aparato tecnológico de projetores e players digitais, dezenas de projecionistas perderam seus empregos, descompassados na operação das novas 
máquinas e, envoltos numa espécie de delay, pois seu movimento de partilha de saberes não acompanhou o ritmo das novas demandas. Entre 2009 e 2016, Gonçalves realizou diversas entrevistas com projecionistas como parte de um processo de pesquisa vinculado ao seu Trabalho de Conclusão de Curso da graduação; e, por conta de vivências na Cinemateca Brasileira, entre 2009 e 2013, conviveu e trabalhou com os operadores cinematográficos. Nesse processo, apostou num modo de pesquisar cartográfico, compreendendo o método como parte do percurso, ou seja, as decisões não estão dadas a priori, mas, construídas ad hoc, de modo que os movimentos e as rupturas foram tomados como imanentes ao processo da pesquisa. Em sua análise, apropriou-se da ideia de ondas de destruição do crítico francês Raymond Borde, com a finalidade de discutir como as mudanças tecnológicas afetaram historicamente as decisões relativas ao descarte dos materiais fílmicos e como os operadores cinematográficos se inserem em tal contexto. Por fim, a análise desdobra-se no que a autora denomina de um jogo de dados educacional, no qual expõe detalhamentos e diferenças percebidas nos modos de condução das conversações com os projecionistas.

No texto Processos de construção do espaço e do corpo brincante: recepção, contaminação e aprendizagem na festa do coco, fruto da dissertação de mestrado de Petícia Carvalho de Moraes, aborda-se a Festa do coco, que acontece todo último sábado de cada mês nas comunidades quilombolas do Ipiranga e Gurugi, localizadas no município paraibano do Conde. $\mathrm{O}$ foco da autora é discutir as relações de aprendizado entre os brincantes no decorrer da festa; aprendizado denominado por ela de contaminação, que se inicia quando o brincante entra na roda desejando aprender a execução do passo básico: o participante observa os movimentos das pessoas na brincadeira e contamina-se das características desses movimentos. Por meio da Estética da Recepção de Hans Robert Jauss, a autora argumenta que os líderes da Festa do Coco encontraram, não por orientação pedagógica, mas pela lógica da própria brincadeira, um caminho para produzir arte.

Em Olhar, movimento, Gavin Adams apresenta a construção de sujeitos observadores e sua relação com a realidade das imagens a partir de provocações suscitadas por um artigo de Jan Masschelein (E-ducando o olhar: a necessidade de uma pedagogia pobre); construção esta cruzada com elementos de seus estudos sobre a estereoscopia. Partindo de "três tipos de sujeito", Adams esboça uma interação destes com o problema do sujeito observador no contexto dos estudos estereoscópicos. A busca de autores como Masschelein e Frederic Gros (Caminhar, uma filosofia) envolve a crítica de um tipo de olhar que mira uma realidade dada e definida à sua revelia, com separação entre sujeito e objeto, entre observador e observado. Ao ponderar como definir o movimento sem incorrer em espacialidade, isto é, como (re)definir o movimento sem recorrer à ideia de espaço previamente dado, o autor sustenta que precisaremos definir o movimento não como "uma sucessão de posições no espaço". Nesse sentido, o tipo de observador que realiza parcialmente este tipo de incorporação é o observador binocular (estereoscópico), e o presente texto busca aproximações entre o observador estereoscópico e o olhar "em movimento" de Masschlein.

Esse dossiê resulta, portanto, de tentativas, à maneira de ervas daninhas que crescem esparramando-se, transtornar hábitos educativos para repensar e recriar práticas educacionais, transformando problemas em novas situações ou, melhor, transformando problemas em outros problemas e questionando seus/nossos olhares com o intuito de compor possibilidades de deslocamento na experiência da docência e da pesquisa de cada um/a. 